\title{
Movimientos estudiantiles en cuestión: 100 años de lucha, 100 años de estudio
}

\author{
Juan Antonio Gutiérrez-Slon* \\ https://orcid.org/0000-0001-8135-3390
}

Recibido: 11 de enero de 2020 • Aceptado: 20 de marzo de 2020

\section{Resumen}

El artículo reflexiona sobre las cualidades teóricas y analíticas en el estudio de los movimientos estudiantiles en el contexto de América Latina. Este esfuerzo hermenéutico, sustentado en una extenuante revisión bibliográfica, especializada en la temática que giran alrededor de las discusiones sobre los movimientos sociales, muestra las formas y espacios de organización, las expresiones del movimiento estudiantil, sus demandas políticas y la organización virtual como nueva forma de comunicación política. De esta manera, en el artículo se encuentran las más importantes referencias académicas para comprender este fenómeno en su compleja composición social y política, según los exponentes intelectuales latinoamericanos.

Palabras clave: Organizaciones de estudiantes, autonomía educativa, estudiante universitario, América Latina.

\footnotetext{
* Máster en Historia de la Universidad de Costa Rica (UCR), de Costa Rica. Bachiller en Sociología de la Universidad Nacional Autónoma (UNA), de Costa Rica. Investigador del Centro de Investigaciones en Cultura y Desarrollo (CICDE) y del Centro Agenda Joven en Derechos y Ciudadanía, ambos de la Universidad Estatal a Distancia (UNED), de Costa Rica. Correo: jgutierrez@uned.ac.cr
} 
Student Movements in Question: 100 years of struggle, 100 years of research

\begin{abstract}
This article reflects on the theoretical and analytical qualities in the study of student movements in the Latin American context. This hermeneutical endeavor, based on a strenuous bibliographical review, specialized in the issues that revolve around the discussions on social movements, shows the organizational forms and spaces, expressions of student movements, their political demands and virtual organization as a new form of political communication. Thus, in this article the most important academic references will be found in order to better understand this phenomenon in its complex social and political composition, according to leading Latin American intellectual exponents.
\end{abstract}

Key words: Student Organizations, Educational Autonomy, University Student, Latin America.

\title{
Les mouvements étudiants en question: cent ans de lutte et cent ans d'étude
}

\section{Résumé}

Cet article réfléchi sur les qualités théoriques et analytiques dans l'étude des mouvements étudiants dans le contexte de l'Amérique Latine. Ce travail herméneutique basé sur une exhaustive révision bibliographique spécialisée dans la thématique qui est autour des discussions sur les mouvements sociaux. Ces discussions mettent en évidence les formes et les espaces d'organisation, les expressions du mouvement étudiant, leurs demandes politiques et l'organisation virtuelle comme une nouvelle manière de communication politique. C'est ainsi que l'article présente les références académiques les plus importantes pour comprendre ce phénomène dans sa complexe composition sociale et politique, selon les représentants intellectuels de l'Amérique Latine.

Mots-clés: Organisations d'étudiants, autonomie éducative, étudiant universitaire, Amérique Latine. 


\section{Introducción}

En el marco de la investigación A cien años de la Reforma de Córdoba: luchas y acciones colectivas de movimientos estudiantiles universitarios en América Central, 1918-2018, del Centro Agenda Joven en Derechos y Ciudadanía de la Universidad Estatal a Distancia (UNED), de Costa Rica, se presenta un análisis sobre los principales acercamientos epistemológicos que se han realizado sobre movimientos estudiantiles en el contexto de América Latina. ${ }^{1}$

En este análisis conjunto sobre los enfoques teóricos, empíricos y temáticos se ha reflexionado sobre los movimientos estudiantiles latinoamericanos entre 1918 y 2018, por el centenario de la Reforma de Córdoba, y ligado con la forma en cómo la producción académica ha interpretado, documentado y analizado la lucha estudiantil universitaria como parte de la historia política de América Latina. Las explicaciones conceptuales que engloban este artículo son presentadas en forma continua, según los contenidos expuestos por las personas autoras citadas, sin que se pretenda realizar un debate entre sus argumentos; sino, su aparición es con el fin de contraponer sus visiones y versiones de los movimientos estudiantiles según las cualidades epistemológicas propias de cada referencia. En este aspecto, son sus enfoques de análisis teórico-metodológicos, y no tanto sus presiones históricas o contextuales, lo que se analiza en el artículo.

Al partir de este amplio material hermenéutico, el texto inicia con el apartado de «La Reforma de Córdoba y el estudio de luchas estudiantiles», el cual incluye el estudio de la lucha inicial en 1918; luego, se exponen casos concretos del continente, explicados en los subapartados «Luchas universitarias y rupturas juveniles de 1968» $\mathrm{y}$ «El cogobierno estudiantil: la centenaria consigna universitaria».

En el apartado «Acercamientos teóricos sobre movimientos estudiantiles» se integra una amplia reflexión, en la cual se hace énfasis en aspectos conceptuales y triangulaciones teóricas, para luego profundizar en el subapartado «Luchas estudiantiles desde las acciones colectivas y los movimientos sociales»; se cierra con las «Conclusiones», en la que dota de reflexiones finales este centenario de luchas estudiantiles.

Este tipo de análisis amplía en las manifestaciones de los movimientos estudiantiles desde sus connotaciones sociales y culturales específicas, constitutivas no solo de acciones de protesta, sino de un conjunto humano complejo. Debido a esta constancia de la lucha estudiantil, se han realizado compilaciones académicas integradas en el «Anexo», donde se presentan, paralelamente, las luchas estudiantiles en varios países del continente y el importante aporte de este tipo de esfuerzos académicos que permite pensar en conjunto a la región de América Latina.

Finalmente, se debe agregar que este aporte desde Agenda Joven es parte de otros resultados obtenidos con la investigación global previamente mencionada, razón por

\footnotetext{
${ }^{1}$ Este artículo es parte de los productos devenidos del proyecto de investigación mencionado, realizado en el 2018, en el marco del centenario de la Reforma de Córdoba. El proyecto ha incluido otras publicaciones, realización de coloquios internacionales, procesos formativos, conferencias y una serie web en video, entre otros resultados accesibles mediante las plataformas sociales en línea del Centro Agenda Joven. El equipo de investigación estuvo conformado por la Licda. Nora González Chacón (politóloga y abogada), el Lic. Anthony García Marín (sociólogo) y el autor de este artículo, M.Sc. Juan Antonio Gutiérrez Slon (sociólogo e historiador).
} 
la cual, metodológicamente, este artículo surgió como orientación para ubicar cuáles han sido los abordajes teóricos centrales que se han realizado desde América Latina sobre los movimientos estudiantiles universitarios, más allá de la posibilidad de generar una historia general o distinguir puntualmente cuáles han sido las transformaciones de los movimientos estudiantiles en la región.

De esta manera, el método seguido fue la hermenéutica sobre las formas epistemológicas (teóricas y metodológicas), en las cuales se han sustentado cien años de estudio de movimientos estudiantiles universitarios latinoamericanos. Por este motivo, no es posible explicar cada contexto nacional ni tampoco debatir sobre cuál método es mejor, sino, contraponerlos desde una escritura saturada en fuentes, que permita, a quienes leen el texto, discernir ángulos analíticos sobre este problema de estudio.

Para lograr este abordaje teórico del problema, fue necesaria la búsqueda, lectura y comprensión de cientos de fuentes secundarias disponibles en los buscadores académicos de la región: Scielo, Latindex, Redalyc, Dialnet, JSTOR, CLACSO; así como consultas en bibliotecas académicas de Costa Rica. De esta exhaustiva búsqueda, se seleccionaron más de 500 referencias centrales, las cuales fueron ordenadas y estudiadas con apoyo del software Zotero, desde el cual se compilaron, según las principales características de los artículos, las siguientes: autonomía universitaria; movimientos estudiantiles latinoamericanos; movimientos estudiantiles en América Central; concepciones teóricas. De esta manera, cada compilación fue presentada en un producto académico, siendo la categoría sobre lo teórico, el situado en este artículo.

\section{Desarrollo. La Reforma de Córdoba y el estudio de luchas estudiantiles}

Los estudios sobre movimientos estudiantiles han puesto atención central en comprender los hechos iniciales de la Reforma de Córdoba de 1918, enfocados en luchas por la autonomía universitaria, el cogobierno estudiantil, la libertad de cátedra, la injerencia de la universidad en los problemas sociales, así como la separación de la universidad de otras instituciones dominantes, como el ejército, los partidos políticos y la iglesia.

Este hito histórico es el evento que marcó la ruptura más importante para la configuración moderna de los movimientos estudiantiles y ha sido el acontecimiento más estudiado en el tema. En este aspecto -dentro de la variada bibliografía que se refiere o reseña esta lucha- están los trabajos ${ }^{2}$ de Dardo Cúneo, La reforma universitaria (1918-1930), Juan Carlos Portantiero (1978), Estudiantes y política en América Latina. El proceso de la reforma universitaria (1918-1938), y Juan Villareal (1971), La reforma universitaria, en los que no solo se explica la lucha original de Córdoba en 1918, sino la inspiración para que en otras partes del continente latinoamericano se impulsaran procesos de reforma que hicieran de las

${ }^{2}$ Dardo Cúneo (compilador), La reforma universitaria (1918-1930) (Caracas: Biblioteca Ayacucho, 1978); Juan Carlos Portantiero, Estudiantes y política en América Latina. El proceso de la reforma universitaria (1918-1938) (México: Siglo Veintiuno Editores, 1978); Juan Villareal, La reforma universitaria (Caracas: Biblioteca Ayacucho, 1971). 
universidades públicas centros de enseñanza autónomas en sus decisiones políticas, financieras, curriculares e ideológicas.

Las consignas de autonomía universitaria originadas en Córdoba, Argentina, fueron reproducidas por estudiantes universitarios de otros países, en un proceso que abarcó tanto la década de 1920 como las de 1930 y 1940, en lo que sería una oleada de procesos reformistas emprendida por todo el continente. Al respecto, Cúneo ${ }^{3}$ y Portantiero ${ }^{4}$ concuerdan en que el alcance de esta lucha no solo se extiende hacia otras universidades, sino que se extiende en el tiempo y en el abordaje de toda la sociedad 5 .

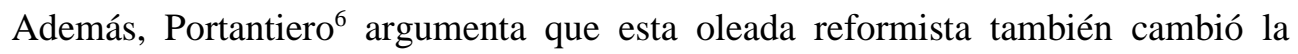
condición propia de la juventud al constituirse como actor político en las sociedades modernas; argumento que replica Sergio Balardini al considerarla como una ruptura política-generacional de la juventud universitaria, que sintetiza al decir que «antes de 1918, existían jóvenes sin juventud» ${ }^{7}$, al llevar el análisis de la nueva constitución social de la persona joven y la juventud como conjunto histórico.

La Reforma de Córdoba fue puente para otros procesos políticos emprendidos por estudiantes universitarios, quienes, como parte de los sectores intelectuales -según Portantiero $^{8}$-, emprendieron procesos políticos anticlericales, antiimperialistas y opositores a los regímenes dictatoriales ${ }^{9}$. Asimismo, desde la Reforma de Córdoba las luchas estudiantiles para conquistar la autonomía universitaria marcarían una tendencia entre las convicciones de universitarios y universitarias de toda la región latinoamericana durante el siglo XX.

En este sentido, en Colombia, según reseña Orlando M. Martínez ${ }^{10}$, cientos de estudiantes realizaron un movimiento de protesta conocido como el Paro estudiantil de 1938, que consistió en la oposición de personas jóvenes universitarias frente a medidas de modernización y secularización impulsadas por el gobierno del momento.

\footnotetext{
${ }^{3}$ Cúneo, La reforma universitaria...

${ }^{4}$ Portantiero, Estudiantes y política...

${ }^{5}$ Cúneo comprueba esta situación con un amplio registro documentado desde las actas, cartas, pronunciamientos, elecciones y protestas realizadas por estudiantes universitarios entre 1918 y 1930.

${ }^{6}$ Portantiero, Estudiantes y politica...

${ }^{7}$ Sergio Balardini, Mutacions del moviment juvenil a l'Argentina: Córdoba, 'cordobazo' $i$ després, en Joves entre dos mons. Movimients juvenils a Europa i a América Llatina, ed. por Carles Feixa y Joan R. Saura (Barcelona, Generalitat de Catalunya/ Universitat de Lleida, 2000). Citado por Yanko González Cangas «Qué los viejos se vayan a casa. Juventud y vanguardias en Chile y América Latina», en Movimientos Juveniles. De la globalización a la antiglobalización, ed. por María del Carmen Costa González, Joan Saura y Carles Feixa Pàmpols (coords.) (Barcelona: Ariel, 2002), 60.

${ }^{8}$ Ibíd.

${ }^{9}$ Para más detalles sobre esta reforma, entre los que se incluye una perspectiva generacional, la influencia de las ideologías políticas y el cambio cultural que trajo consigo la Reforma, consultar: Yanko González Cangas «Qué los viejos se vayan a casa. Juventud y vanguardias en Chile y América Latina», en Movimientos Juveniles. De la globalización a la antiglobalización, ed. por María del Carmen Costa González, Joan Saura y Carles Feixa Pàmpols (coords.) (Barcelona: Ariel, 2002).

${ }^{10}$ Martínez, Orlando Moreno, «El paro estudiantil de mayo de 1938», Anuario Colombiano de Historia Social y de la Cultura 36 (2) (2009): 41-63. 
En esta línea de acciones universitarias directas desde una vinculación con el contexto latinoamericano, sobresale el aporte de María Eugenia Bordagaray sobre el movimiento estudiantil en Argentina entre 1935 y 1950, donde se presenta evidencia para asegurar que desde lo estudiantil se fortalece la politización de las generaciones jóvenes ${ }^{11}$. Bordagaray analiza la doble pertenencia de militantes en el tanto estudiantes influenciados por el movimiento de la Reforma, al momento que se adhieren a ciertas definiciones ideológicas como el anarquismo ${ }^{12}$.

De forma similar, al final de la década de 1950, según explica Juan Sebastián Califa, el estudiantado argentino levantaría un movimiento crítico sobre la reestructuración universitaria en sus planes educativos concentrados en lo que se conoció como el Plan Cafade, al que consideraban imperialista. En esta ocasión, la oposición estudiantil movilizada por el posicionamiento antiimperialista encontró en una iniciativa curricular, epistémica y educativa, que el movimiento estudiantil hizo propia para elevar una acción de protesta entre 1959 y $1960^{13}$.

En otros escenarios políticos análogos, están las huelgas universitarias en el estado mexicano de Michoacán, entre 1956 y 1966, que ampliamente reseñó Antonio Gomes Nashik, y sobre las cuales afirma que tuvieron importantes repercusiones en la dinámica estatal del contexto. En este caso, el movimiento estudiantil se movilizó desde un variado repertorio de luchas mediante huelgas, paros, manifestaciones y mítines, que se fueron dando en la Universidad Michoacana de San Nicolás de Hidalgo (UMSNH) por período de una década, los cuales tuvieron como motivación la lucha contra la carencia de recursos financieros y materiales en la universidad ${ }^{14}$.

Estas acciones de lucha estudiantil en Michoacán, más las comentadas de Argentina y Colombia, van configurando una imagen global del movimiento estudiantil, en la que el estudiantado emprende acciones de lucha para intervenir en sus centros de estudio, adherirse a motivaciones ideológicas y la lucha por un cambio general de su contexto político y social. Hechos que irían sumando en organización y tuvieron destacadas generaciones universitarias que protagonizaron las jornadas de protesta de 1968 en varios países del mundo.

\section{Luchas universitarias y rupturas juveniles de 1968}

Con las transformaciones surgidas después de la Segunda Guerra Mundial, las sociedades modernas comenzaron a tener cambios en la integración generacional de jóvenes en el ámbito de la política. De esta manera, las décadas de 1950 y 1960

\footnotetext{
${ }^{11}$ María Eugenia Bordagaray, «Anarquismo y movimiento universitario en Argentina, 1935-1950», Revista CS 9 (2012): 309-332, acceso: 14 de julio de 2020, http://www.redalyc.org/articulo.oa?id=476348372010

${ }^{12}$ Estas acciones estudiantiles se fueron diversificando en las distintas organizaciones del movimiento social y los procesos políticos de Argentina a mediados del siglo XX. Esto trae consigo un influjo en varios procesos políticos que no se hubieron podido llevar a cabo sin el movimiento estudiantil.

${ }^{13}$ Juan Sebastián Califa, «El movimiento estudiantil reformista contra el Plan Cafade. Cientificismo, imperialismo, reestructuración universitaria y lucha política (1959-1960)», Redes 32 (2011): 61-184, acceso: 14 de julio de 2020, http://www.redalyc.org/articulo.oa?id=90722371006

${ }^{14}$ Antonio Gómez Nashik, «1956-1966: huelgas estudiantiles en la Universidad de Michoacán», Universidades 61 (2014): 19-36, acceso: 14 de julio de 2020, http://www.redalyc.org/articulo.oa?id=3733303900420

ESPIGA @)(1) (1) Año 20, N. ${ }^{\circ} 40: 24-56$, julio - diciembre 2020 
presentaron mayor estabilidad en la cobertura de servicios básicos para un sector importante de la población europea y americana; esto posibilitó una acción más activa de las juventudes universitarias (urbanas y mesocráticas) con un mayor acceso a conocimiento y niveles de participación política ${ }^{15}$.

Es en este aspecto, para finales de la década de 1960 y en el contexto de la Guerra Fría, en varias partes del mundo se presenciaron rebeliones sociales, políticas y culturales protagonizadas por personas jóvenes $\mathrm{y}$, consecuentemente, por universitarios y universitarias, en lo que el historiador británico Erick Hobsbawm llamaría «la mayor revolución cultural de la segunda mitad del siglo $\mathrm{XX}{ }^{16}$.

De esta manera, 1968 fue el año de mayor proliferación de la lucha universitaria y juvenil, donde se apelaba a cambios radicales en las sociedades que pudieran generar mayor distribución de la riqueza, evitar la crisis ambiental, elevar la cobertura en servicios sociales y construir sociedades más democráticas, donde estuviesen garantes los derechos humanos. 1968 se convertiría en el año hito de la rebelión juvenil.

Debido a este álgido contexto de luchas estudiantiles universitarias, la producción académica de estas también es abundante. Algunas responden al mismo momento en que se dieron los acontecimientos e, incluso, fueron escritos por sus mismos protagonistas, como los de Barbara y Jhon Ehrenreich ${ }^{17}$ y Cohn-Bendit ${ }^{18}$, en los cuales se detallan las protestas de estudiantes de la Universidad de Berkeley (Estados Unidos) y en la Sorbona, en París (Francia), respectivamente ${ }^{19}$.

En este aspecto, hay una relación de una juventud universitaria -por lo menos en el mundo occidental ${ }^{20}$ - que emprendió importantes protestas en 1968 y los años subsiguientes. Uno de estos movimientos estudiantiles, y de los más documentados, fue el caso mexicano, que implicó la muerte de decenas de estudiantes a manos del

${ }^{15}$ Eric Hobsbawm, Historia del Siglo XX. 1914-1991 (Barcelona: Crítica, 2006), 322-344.

${ }^{16}$ Ibíd., 322.

${ }^{17}$ Bárbara y Jhon Ehrenreich, Itinerario de la Rebelión Estudiantil, traducción de Javier Guerrero (México: Editorial Nuestro Tiempo S.A., 1969).

${ }^{18}$ Cohn-Bendit Sauvageot, La rebelión estudiantil (México: Serie Popular ERA, 1969).

${ }^{19}$ En otros textos importantes de comentar sobre 1968, están las producciones de algunos de los mismos intelectuales con los cuales se intervino en estas luchas como Herbert Marcuse. La rebelión de los estudiantes (Buenos Aires: Paidós, 1969), y Herbert Marcuse, El fin de la utopía (México: Siglo Veintiuno Editores S.A., 1971), donde publica sobre los importantes acontecimientos de 1968 y amplía en las condiciones sociales, políticas y culturales que llevaron al levantamiento estudiantil y que traería importantes cambios en las sociedades modernas. Otras referencias con similar abordaje son: Carlos Fuentes, Jean Paul Sartre y otros. La revolución estudiantil (San José: Editorial Universitaria Centroamericana / EDUCA, 1971), así como Pedro Ibarra y Noemi Bergantiños, «Movimientos estudiantiles: de mayo del 68 a la actualidad. Sobre las Experiencias utópicas de un movimiento peculiar», en Movimientos estudiantiles: resistir, imaginar, crear en la universidad, ed. por Xabier Albizu Landa, Joseba Fernández González y Jon Bernat Zubiri Rey (Barcelona: Gakoa, 2-18).

${ }^{20}$ No obstante, los movimientos estudiantiles universitarios en el contexto de 1968 -aunque en menor grado- también se dieron en sociedades asiáticas como Japón o Vietnam, al igual que en sociedades africanas. Para ampliar sobre el caso africano ver: Pablo Bonavena, «Epílogo. Los estudiantes africanos durante 1968: las luchas en Sudáfrica, Senegal y Túnez», en Los 68 latinoamericanos, ed. por Pablo Bonavena y Mariano Millán (Buenos Aires: CLACSO, 2018), acceso: 14 de julio de 2020, https://www.jstor.org/stable/j.ctvn5tzpt.14 
ejército que les arremetió en la plaza de Tlatelolco, en un contexto de represión contra la Universidad Nacional Autónoma de México ${ }^{21}$.

Del trágico desenlace del 2 de octubre de 1968, existen importantes documentos académicos que los reseñan, recuerdan y conmemoran desde distintas metodologías. Uno de estos es el de Ramón Ramírez ${ }^{22}$, que realiza una amplía compilación de documentos, conferencias, peticiones, acuerdos, proclamas y cartas que, ordenadas día a día, muestran el ciclo de protestas contra el gobierno autoritario de Gustavo Díaz Ordaz. Esta compilación documental de Ramírez se asemeja a la compilación fotográfica comentada por Eugenia Allier Montaño, en la que reseña lo sucedido mediante fotos que muestran la masacre y el legado de la protesta estudiantil del $68^{23}$.

No obstante, en Latinoamérica este no fue el único caso. Hay estudios que reseñan otras acciones estudiantiles de 1968 como lo fue el caso uruguayo que investiga Vania Markarian, en el que muestra una lectura sobre el movimiento estudiantil, sus integrantes y las relaciones que mantuvieron con las luchas de izquierda uruguayas y latinoamericanas. Markarian ${ }^{24}$ afirma que la movilización estudiantil precede a su organización en los partidos políticos donde hay una autonomía de la lucha estudiantil a la del partido.

Similar a los casos mexicanos y uruguayos, en el contexto del 68, se encuentra el estudio de Martín Mangiantini, en el cual estudia la relación entre el movimiento estudiantil de la Universidad de Buenos Aires y el Partido Revolucionario de los Trabajadores-La Verdad (PRT-LV), entre 1968 y 1972. En este estudio se muestra que, en un contexto de dictadura militar, hubo movilizaciones de diferentes actores sociales como el sindicalismo, movimientos culturales, colectivos intelectuales y hasta corrientes religiosas como la teología de la liberación, con los cuales el movimiento estudiantil universitario se unió en una lucha desde una postura autónoma ${ }^{25}$.

${ }^{21}$ La protesta estaba siendo dirigida por personas universitarias, pero también hubo presencia de obreros, docentes, vecinos y población en general, aunque en menor medida que el estudiantado.

${ }_{22}$ Ramírez, Ramón, El movimiento estudiantil de México. Julio-diciembre de 1968 (tomos I y II) (México: Ediciones Era, 1969).

${ }^{23}$ Similar a estos esfuerzos de compilación y explicación de los acontecimientos de las protestas en 1968, se encuentran entrevistas y memorias de protagonistas que llevan a varias formas de remembrar estas luchas y la masacre del 2 de octubre de 1968. Adolfo Vázquez Sánchez, «El movimiento del 68. Testimonio y Reflexiones», Sociológica 13 (38) (1998): 145-152). Además, se localizan algunas producciones cortas y otras largas, que depende de las intenciones que se quiere seguir o explicar Troncoso, Alberto del Castillo. «Daniel Luna Cárdenas y Paulina Martínez Figueroa (investigación visual), La academia de San Carlos en el movimiento estudiantil de 1968, ENAP-UNAM, México», Secuencia. Revista de historia y ciencias sociales 74 (2009): 172-175, acceso: 14 de julio de 2020, http://www.redalyc.org/articulo.oa?id=319127432008

${ }^{24}$ Vania Markarian, «Sobre viejas y nuevas izquierdas. Los jóvenes comunistas uruguayos y el movimiento estudiantil de 1968», Secuencia. Revista de historia y ciencias sociales 81 (2011): 169, acceso: 14 de julio de 2020, http://www.redalyc.org/articulo.oa?id=319127440007

${ }^{25}$ Martín Mangiantini, «PRT-La verdad y el movimiento estudiantil argentino. Hacia un análisis de las estrategias de inserción y de las tensiones existentes (1968-1972)», Revista Izquierdas 23 (2015): 84, acceso: 14 de julio de 2020, http://www.redalyc.org/articulo.oa?id=360135258005 
De forma paralela, en Colombia, hay producciones académicas que explican las luchas universitarias de gran impacto histórico, como el movimiento suscitado en 1971 para obtener el cogobierno estudiantil en la Universidad Nacional de Cali. Sobre esta lucha, Álvaro Acevedo Tarazona ${ }^{26}$ comenta que la movilización se había agrupado en rechazo al control que una entidad privada había ejercido sobre el déficit presupuestario universitario que se tenía en esos años, lo que llevó a proclamar el derecho al cogobierno estudiantil ${ }^{27}$.

Con estas referencias sobre movimientos estudiantiles en América Latina, se torna evidente que un impulso motivador por los que las personas universitarias emprenden luchas surge desde sus propias casas de estudio, alrededor de la ausencia o presencia del cogobierno estudiantil. Este es un eje constante de lucha estudiantil que se ampliará en el siguiente apartado. Asimismo, estas referencias se incluyen como parte de las diferentes formas epistemológicas con las cuales se han estudiado las décadas de 1960 y 1970, haciéndose imposible, para este artículo, contextualizar cada lucha estudiantil según sus propias coyunturas, por lo que se opta por una elección de fuentes que se hayan acercado a 1968, desde métodos diferentes, sean estos, biográficos, fotográficos, ideológicos, pragmáticos u otros, con los cuales se puede comprender lo amplio de la movilización estudiantil en este año y lo variado de sus repertorios de lucha.

\section{Cogobierno estudiantil: la centenaria consigna universitaria}

La lucha estudiantil originada en 1918, en Córdoba, transformó por completo la lógica universitaria, gracias a que logró el cogobierno estudiantil en el modelo político de estas instituciones. En este cambio radica la esencia misma de los movimientos estudiantiles universitarios latinoamericanos modernos, ya que son los ejes centrales del fenómeno mismo y, por ende, de los estudios que se realizan sobre este tema. En este aspecto, el trabajo de la politóloga argentina Victoria Kandel ${ }^{28}$ presenta un importante análisis entre la continuidad y el cambio de las estructuras universitarias de los movimientos estudiantiles, al argumentar que, aun en las universidades más antiguas y tradicionales, se encuentra la contradicción entre «nuevos actores en viejas estructuras», con lo cual la lucha estudiantil construye su

\footnotetext{
${ }^{26}$ Álvaro Acevedo Tarazona, «Modernización universitaria y protesta estudiantil en Colombia: el caso de la Universidad Industrial de Santander (1953-1977)», Anuario de Historia Regional y de las Fronteras 17 (2) (2012): 371-399, acceso: 14 de julio de 2020, http://www.redalyc.org/articulo.oa?id=407539692012. Acevedo Tarazona narra los hechos de la protesta relacionada con la defensa de la autonomía, la modificación del Consejo Superior Universitario y el presupuesto, a la vez que apunta la conexión de varias universidades del país y cómo la movilización se fue reforzando con asambleas, foros y tomas.

${ }^{27}$ Este estudio sobre la conquista del cogobierno en la Universidad Nacional se acompaña de otro del mismo Acevedo, que publica en el 2011: Álvaro Acevedo Tarazona, «El movimiento estudiantil como objeto de estudio en la historiografía colombiana y continental: notas para un balance y una agenda de investigación», Historia y Memoria, Núm. 3, 2011, acceso: 22 de julio de 2020, https://revistas.uptc.edu.co/index.php/historia_memoria/article/view/799

${ }^{28}$ Victoria Kandel, «Participación estudiantil y gobierno universitario: nuevos actoresviejas estructuras», tesis de maestría en Ciencias Sociales, con Orientación en Educación (Buenos Aires: FLACSO, 2005), acceso: 22 de julio de 2020, http://propuestaeducativa.flacso.org.ar/wpcontent/uploads/2019/12/resen\%CC\%83a_tesis_Kandel_PE28.pdf 
propia historia como elemento distintivo de las sociedades modernas, en las que se muestra la política estudiantil universitaria ${ }^{29}$.

En otro estudio, Kandel ${ }^{30}$ sustenta la tesis de que el estudiantado que participa activamente de los cargos de poder presentes en el cogobierno estudiantil universitario, «encarna la posibilidad de acumular un capital social que los diferenciará del conjunto de los estudiantes». A lo que agrega, como razones de la participación «las siguientes: interés en acceder a información y divulgarla, entrelazarse con las altas esferas de la política universitaria, lograr aprendizajes políticos, y creencia en la posibilidad de llevar a cabo un proyecto colectivo transformador a través de la militancia» ${ }^{31}$.

$\mathrm{Al}$ seguir con este elemento transformador del movimiento estudiantil, tanto de su entorno en los colectivos de la universidad y sociedad como de los individuales en las biografías de sus protagonistas, se encuentra el aporte de la chilena Micaela Lobos Roco sobre la prolongación en la acción política de representantes estudiantiles. En su estudio, la autora realizó un seguimiento a la trayectoria biográfica de 36 presidentes de la Federación de Estudiantes de la Universidad de Chile (FECH) entre 1984 y 2005, y concluye que, durante sus etapas de vida de juventud universitaria, existió una transformación por medio de la carrera política, siendo esta la trayectoria de vida que siguieron para sí mismos ${ }^{32}$. En el caso colombiano -y como cierre al apartado dedicado al cogobierno- se encuentra el estudio de Edwin Cruz Rodríguez, que reflexiona sobre los movimientos estudiantiles que en 2011 libraron una lucha anti-privatizadora de la educación superior por medio de una estructura unitaria de grupos estudiantiles llamada Mesa de Unidad Nacional (MANE). Este espacio político estudiantil se encargó de organizar un gran paro universitario llamado la Toma de Bogotá. Esta lucha, según Cruz, fue posible debido a la figura de la «asamblea estudiantil» como eje articulador en la organización política universitaria y como espacio garante de la participación directa del estudiantado en la toma de decisiones sobre el movimiento de protesta, donde hay tendencias de horizontalidad y cuotas de representación que hacen legítima la lucha estudiantil a nivel nacional. Cruz Rodríguez ${ }^{33}$ explica que en esta ocasión:

\footnotetext{
${ }^{29}$ Otro estudio similar a este, es el realizado por Susana Beatriz Argüello, que desde un punto de vista comparativo relaciona la lucha universitaria de 1918, en Córdoba, y las acciones realizadas por la Federación Universitaria Argentina (FUA) hacia inicios del siglo XXI. Esta referencia se encuentra en el artículo «Movimiento estudiantil, política de educación superior y exclusión educativa», impreso en Cuadernos de la Facultad de Humanidades y Ciencias Sociales, Universidad Nacional de Jujuy, núm. 30, julio, 2006, pp. 13-40, Universidad Nacional de Jujuy, Jujuy, Argentina.

${ }^{30}$ Victoria Kandel, «Gobierno universitario y participación estudiantil. Consideraciones sobre el cogobierno y la democracia en la universidad pública», Propuesta Educativa 34 (2010): 103, acceso: 14 de julio de 2020, http://www.redalyc.org/articulo.oa?id=403041705010

${ }^{31}$ Ibíd.

${ }^{32}$ Micaela Roco Lobos, «La influencia de las organizaciones políticas universitarias en la formación de élites políticas en Chile: el caso de las federaciones de estudiantes de la Universidad de Chile y Universidad Católica 1984-2005», Política 54 (2) (2014): 159, acceso: 14 de julio de 2020, http://www.redalyc.org/articulo.oa?id=64537763006

${ }^{33}$ Edwin Cruz Rodríguez, «La reforma de la educación superior y las protestas estudiantiles en Colombia», Postdata 18 (2013): 54, acceso: 14 de julio de 2020,
} 
La MANE reúne cerca de 300 procesos organizativos nacionales, regionales y locales; tiene una estructura horizontal, compuesta por la plenaria, el Comité Operativo y las comisiones de comunicaciones, derechos humanos y académica; y un funcionamiento asambleario con mesas de trabajo organizativa, programática y de movilización. Ha tenido que enfrentar distintas tensiones para conservar la unidad: por la toma de decisiones, entre grandes y pequeñas organizaciones o sectores no organizados, alrededor de las vocerías y entre la MANE y las regiones.

De esta manera, las luchas estudiantiles universitarias en América Latina muestran continuidad como actores políticos autónomos y determinantes en el continente. Por esta razón es necesario aumentar los niveles de comprensión sobre estos, situación que coloca, a quienes investigan, frente a la necesidad de reflexionar sobre los enfoques teóricos generales desde los que han sido estudiados; este es el componente del siguiente apartado.

\section{Acercamientos teóricos sobre movimientos estudiantiles}

La realización de estudios sobre movimientos estudiantiles universitarios, desde enfoques teóricos asumidos por las ciencias sociales o que tiendan a la teorización desde sus propias cualidades, no suelen ser la tendencia dominante en este tipo de investigaciones $^{34}$, pese a existir importantes esfuerzos en este aspecto.

Desde esta perspectiva, el estadounidense Lewis Feuer ${ }^{35}$ realizó un importante quiebre epistemológico al concebir los movimientos estudiantiles desde una concepción abstracta que le permitió superar sus propias manifestaciones fácticas y ampliar su comprensión como fenómeno social, por lo que ha sido ampliamente citado en estudios similares. Algunos aportes teóricos de Feuer radican en las siguientes percepciones sobre el movimiento estudiantil (cuadro 1):

\section{Cuadro 1 Encuadres teóricos sobre movimientos estudiantiles en Feuer}

\begin{tabular}{|l|l|}
\hline Etapas constitutivas & $\begin{array}{l}\text { Gestación: correspondiente al diálogo entre estudiantes } \\
\text { presentes en las aulas, pasillos y otros espacios donde } \\
\text { intercambian puntos de vista sobre el acontecer universitario, } \\
\text { social y político. }\end{array}$ \\
\hline
\end{tabular}

www.scielo.org.ar/scielo.php?pid=S1851-

$96012013000100002 \&$ script=sci_arttext\&tlng=en

${ }^{34}$ Esto se da en la amplia mayoría de investigaciones y artículos que giran sobre esta problemática. Parten de un método descriptivo, donde la narración de eventos de alguna coyuntura en particular (usualmente de carácter nacional) es comentado históricamente; en algunas ocasiones desde la historiografía, en otras ocasiones como relato de eventos de protestas estudiantiles. Esto se concluye luego de la exhaustiva indagación y lectura documental de todas las fuentes que se integraron en el proyecto del Centro Agenda Joven, así explicado en la introducción.

${ }^{35}$ Lewis Samuel Feur, Los movimientos estudiantiles. Las revoluciones nacionales y sociales en Europa y el tercer mundo (Buenos Aires: Editorial Paidós, 1969). 


\begin{tabular}{|c|c|}
\hline \multirow[t]{3}{*}{ Etapas constitutivas } & $\begin{array}{l}\text { Elección de metas: relacionado con la construcción colectiva } \\
\text { en torno a la causa de lucha y motivación de la protesta } \\
\text { generacional. }\end{array}$ \\
\hline & $\begin{array}{l}\text { Acción estudiantil autónoma: correspondiente a las } \\
\text { manifestaciones en las que se expresa la lucha estudiantil. } \\
\text { Esta suele iniciar en la misma universidad y extenderse a la } \\
\text { ciudad mediante el cierre de calles. }\end{array}$ \\
\hline & $\begin{array}{l}\text { Desarrollo de actitudes políticas e ideológicas: concerniente } \\
\text { al posicionamiento del movimiento estudiantil como } \\
\text { vanguardia de las causas, luchas o demandas populares, ante } \\
\text { lo cual- se lucha en un entorno más amplio de las causas } \\
\text { gremialistas como estudiantes. }\end{array}$ \\
\hline Lucha generacional & $\begin{array}{l}\text { La lucha estudiantil se sostiene sobre la base de la } \\
\text { contraposición entre jóvenes universitarios y la generación } \\
\text { adulta que dirige la sociedad. Se presenta una lucha } \\
\text { generacional que cambia en el tiempo y se manifiesta según } \\
\text { los contextos históricos, sociales y políticos de cada país. }\end{array}$ \\
\hline Conciencia generacional & $\begin{array}{l}\text { Se alimenta de la juventud universitaria que se mira } \\
\text { impulsada por una «rebelión emocional en la que están } \\
\text { presentes la desilusión y el rechazo de los valores de la vieja } \\
\text { generación» } 36\end{array}$ \\
\hline Corta temporalidad & $\begin{array}{l}\text { Debido al carácter pasajero de ser estudiante universitario. } \\
\text { Suelen ser de carácter temporal y transitorio que marca una } \\
\text { generación y luego será reinventada por otros colectivos y } \\
\text { generaciones estudiantiles. }\end{array}$ \\
\hline $\begin{array}{l}\text { Motivación para la } \\
\text { lucha }\end{array}$ & $\begin{array}{l}\text { Se basa en la asimilación de valores supremos como la } \\
\text { justicia, libertad y otros. Los llevan a plantearse como actores } \\
\text { históricos que se miran dirigidos desde un «idealismo } \\
\text { histórico», la ideología del movimiento estudiantil, en la } \\
\text { misma línea que la «lucha de clases» lo es para el } \\
\text { movimiento obrero, es decir, el motor de acción. }\end{array}$ \\
\hline
\end{tabular}

Fuente: Elaboración propia con base en Lewis Feuer.

Debido a estos postulados de Feuer -y que no agotan su propuesta-, este autor se presenta como un referente importante para la comprensión teórica, general y abstracta de los movimientos estudiantiles, más allá de sus expresiones puntuales en una acción colectiva precisa en el tiempo y espacio ${ }^{37}$.

Otra concepción que contiene un apartado teórico sobre la constitución misma del movimiento estudiantil se encuentra en el trabajo del sociólogo chileno José Joaquín

${ }^{36}$ Ibíd., 31.

${ }^{37}$ Para su teorización, Lewis Feuer realizó un análisis sustentado en casos de movimientos estudiantiles en universidades de Europa, algunos países de Asia y América, con especial énfasis en Estados Unidos, que constituye una importante compilación de luchas estudiantiles y amplía sus justificantes teóricos, entrelaza fuentes de archivo documental y postulados de carácter ontológico. 
Brunner, El movimiento estudianti ${ }^{38}$, en el cual se analiza la condición estudiantil como «un estilo de vida» que experimentan las personas jóvenes que ingresan a las universidades. En este trabajo, Brunner explica aspectos constituyentes de los movimientos estudiantiles, que se vinculan tanto con su condición política como por su lugar en la educación superior. Estos elementos se resumen en el cuadro 2.

\section{Cuadro 2 Elementos constitutivos del movimiento estudiantil en Brunner}

\begin{tabular}{|l|l|}
\hline Masificación & $\begin{array}{l}\text { Concerniente a la acumulación de estudiantes que } \\
\text { conviven y se aglutinan en el contexto de las } \\
\text { universidades. }\end{array}$ \\
\hline Diferenciación & $\begin{array}{l}\text { Relacionada con la concepción propia del movimiento } \\
\text { universitario como un cuerpo social diferenciado de } \\
\text { otros grupos sociales. }\end{array}$ \\
\hline Identidad & $\begin{array}{l}\text { Ámbito que se construye entre el marco de la } \\
\text { institución universitaria y las numerosas expresiones } \\
\text { de las culturales juveniles. }\end{array}$ \\
\hline Participación & $\begin{array}{l}\text { Relacionado con los grados de intervención del } \\
\text { estudiantado en el contexto mismo de la política } \\
\text { universitaria. }\end{array}$ \\
\hline Alianzas & $\begin{array}{l}\text { Referido a la vinculación política entre el movimiento } \\
\text { estudiantil con otros actores de su contexto. }\end{array}$ \\
\hline
\end{tabular}

Fuente: Elaboración propia con base en Brunner.

Los aportes de Brunner, junto con los de Feuer, convierten a los movimientos estudiantiles en sujetos pensados desde las ciencias sociales y como fenómenos con vertientes comunes posibles de teorizar. A su vez, un conjunto de estudios sobre luchas estudiantiles se basa en el enfoque de la dimensión generacional, las cuales vendrían a ser parte de la percepción del movimiento estudiantil como grupalidad política de personas jóvenes universitarias. Este es el elemento que explica el mexicano Antonio Nashik ${ }^{39}$ desde una configuración del sentido social en el tiempo.

Nashik explora la condición generacional como elemento argumentativo y explicativo para describir las huelgas universitarias suscitadas entre 1956 y 1966 en la Universidad de Michoacán, en México. Este componente relativo al tiempo histórico, lo lleva a compilar el concepto de sentido de la época como una sensación grupal que viven las personas jóvenes de los movimientos estudiantiles. Esta

\footnotetext{
${ }^{38}$ El artículo de Brunner es parte de la compilación de Juan Carlos Tedesco, Hans Blumenthal y Orlando Albornoz, La Juventud universitaria en América Latina, Caracas: Centro Regional para la Educación Superior en América Latina y el Caribe, 1986. Este libro fue resultado del Seminario Regional sobre los Problemas de la Juventud Universitaria en América Latina, del 29 al 30 de mayo de 1985, en Caracas, Venezuela, organizado por el Centro Regional para la Educación Superior en América Latina y el Caribe y la UNESCO.

${ }^{39}$ Antonio Nashik Gómez, «1956-1966: huelgas estudiantiles en la Universidad de Michoacán», Universidades 61 (2014): 19-36, acceso: 14 de julio de 2020, http://www.redalyc.org/articulo.oa?id=37333039004
} 
sensación compartida sobre la realidad inmediata que se vive como parte de una generación implica que «sus miembros son motivados por la convicción de que su generación debe cumplir una misión histórica en la cual la vieja generación, las otras élites o las otras clases, han fracasado» ${ }^{40}$.

Con esto, el sentimiento generacional, aparte de ser una coyuntura temporal en la etapa del crecimiento de la juventud, se proyecta como parte del posicionamiento político necesario para emprender transformaciones sociales que otras generaciones no lograron realizar. Al respecto, Nashik argumenta ${ }^{41}$ :

Lo que define la dimensión de la generación estudiantil ante un acontecimiento generacional es producto de los «límites» temporales y espaciales de un hecho histórico determinado, del mismo modo que el grado de singularidad de dicho acontecimiento determina el grado de dificultad que tal generación experimentará al intentar comunicarse con las anteriores y las posteriores.

En este aspecto, lo generacional ${ }^{42}$ no se da por sentado, sino que se construye desde la misma acción del colectivo juvenil universitario en medio del contexto histórico, político y social que le rodea desde una sensibilidad cultural. Una referencia similar a este estudio, fue expuesta por el costarricense Juan Antonio Gutiérrez Slon ${ }^{43}$, quien en su tesis de maestría en historia, problematizó el movimiento estudiantil de la Universidad Nacional Autónoma de Costa Rica (UNA) como la sucesión de acciones que, desde el mundo de la vida cotidiana del movimiento estudiantil (entre 1974 y 2015), se fue interviniendo en su contexto histórico y político universitario y nacional, desde acciones políticas en el que se intervienen tanto las estructuras de poder social como sus ámbitos interpersonales como jóvenes, trayendo consigo que la construcción social del movimiento estudiantil se dé desde el aquí y ahora de cada generación universitaria.

Siguiendo este enfoque generacional, se encuentra la propuesta epistemológica de los colombianos Jorge Eliécer Martínez Posada y Diego Fernando Barragán Giraldo, quienes exploran el concepto de multitud como elemento constitutivo de las movilizaciones juveniles y los movimientos estudiantiles. En este artículo de priorización teórica-analítica, los autores explican que la construcción social de las personas jóvenes implica los modos de ser/actuar, los conocimientos, usos sociales y costumbres del sujeto juvenil donde «lo joven, y no propiamente el concepto unívoco de juventud, constituye un abanico de perfiles sociales que identifica modos

\footnotetext{
${ }^{40}$ Ibíd., 22.

${ }^{41}$ Ibíd., 23.

${ }^{42}$ El enfoque que argumenta Nashik también viene desde autores consolidados en esta discusión sobre la construcción social de las generaciones. De Karl Mannheim toma la concepción de que la generación es más un resultado de la dinámica social que la pura sincronía biológica por el nacimiento de sus integrantes, acentuando el peso en el contexto social específico que les amalgama. También referencia a Ortega y Gasset, del cual toma la concepción de que una generación también se define por su relación en la convivencia con otras generaciones.

${ }^{43}$ Juan Antonio Gutiérrez-Slon. Mundos juveniles en movimientos estudiantiles: historia, vida cotidiana y acciones de lucha en la FEUNA, 1973-2012. Tesis de maestría en Historia. Universidad de Costa Rica, 2015.
} 
diversos de asumirse frente al mundo, mediados, sin embargo, por los intereses del mercado y que a juicio de muchos ${ }^{44}$.

De esta manera, la construcción social de la persona joven se debe a un proceso interactivo en el que se re-define una postura diversa y compleja frente al mundo. No obstante, esta condición social de la persona joven está inmersa también en una concepción de multitud narrativa, intersubjetiva y cohesionada en medio de su pluralidad, lo que les permite acercarse a una lectura en la cual los movimientos juveniles y estudiantiles responden a la condición de ser una multitud, al constituirse estos como legión ${ }^{45}$.

Por otro lado, desde una discusión aparte, se encuentra el trabajo de Anna María Fernández Poncela ${ }^{46}$, de suma importancia al situarse en un estudio de caso concreto desde la movida estudiantil \#YoSoy132 de México, en el 2012, cuya motivación era sostener una postura contraria a la candidatura presidencial de Enrique Peña Nieto. En su artículo, Fernández Poncela argumenta que las emociones llegan a englobar la condición de las personas estudiantes que mostraban indignación por el carácter político y personal de este candidato, llevando a que el estudiantado buscara suplir las emociones encontradas mediante la acción política ${ }^{47}$.

Este enfoque emocional, aunque no haya tenido tendencias mayoritarias, ha sido uno de los ángulos que va en ascenso en torno a la comprensión de los movimientos sociales y estudiantiles. Por el contrario, el enfoque de género, y los esfuerzos de teorización de los movimientos estudiantiles desde el género, sí ha venido siendo tendencia en ascenso, constituyendo un importante lugar epistémico emergente y centralmente expuesto por mujeres de la academia latinoamericana.

De esta manera, y buscando resaltar el papel protagónico de las mujeres en la historia de las luchas estudiantiles, se encuentra el estudio de Gloria Armida Tirado Villegas, quien reinterpreta la lucha universitaria por lograr la autonomía en el Estado de Puebla (en México, 1961), desde el aporte de las estudiantes universitarias. La autora vuelve sobre este movimiento estudiantil para evidenciar la participación activa de las mujeres universitarias, a quienes coloca como importantes protagonistas en el cambio que produjo que las autoridades universitarias fueran electas al interno de la misma universidad y no por el gobernador, que era lo que se venía practicando ${ }^{48}$.

\footnotetext{
${ }^{44}$ Jorge Eliécer Posada Martínez y Diego Fernando Barragán Giraldo, «Juventud y multitud: Aproximaciones para abordar los movimientos juveniles», Tabula Rasa 9 (2008): 359, acceso: 14 de julio de 2020, http://www.redalyc.org/articulo.oa?id=39600917

${ }^{45}$ Ibíd., 363. Es la cualidad de que las diferentes juventudes en la historia, mediante sus agrupaciones bajo demandas sociales y políticas, han ido construyendo su propia historia, la cual está sumamente alimentada de la lucha y la acción de los movimientos estudiantiles. 46 Anna María Fernández Poncela, «Movimientos y sentimientos», Revista

Latinoamericana de Estudios sobre Cuerpos, Emociones y Sociedad, 5, (13) (2013): 35-50, Universidad Nacional de Córdoba, Córdoba, Argentina.

${ }^{47}$ La autora realiza este estudio de caso debido a la velocidad con que se propagó esta movida estudiantil, donde los sentimientos de enojo e indignación fueron factores que convocaron a miles de estudiantes para unirse en esta acción, que tuvo una importante expresión virtual. Fernández Poncela argumentó su estudio mediante entrevistas con integrantes del \#YoSoy132 y llevó a comprobar la importancia de las emociones y sentimientos como factores movilizadores para la lucha social y estudiantil.

${ }^{48}$ Gloria Arminda Tirado Villegas, «Puebla 1961, Género y Movimiento Estudiantil», Revista de Estudios de Género. La ventana 5 (39) (2014): 179-207, acceso: 14 de julio de
} 
Otro aporte desde la lectura de género en movimientos estudiantiles, es el trabajo de Mónica García Contreras, que hace un estudio crítico, sumamente argumentado desde lo teórico, y epistemológico en el tanto los estudios sobre movimientos estudiantiles (con énfasis en los casos mexicanos) han evitado el estudio formal desde la participación de las mujeres en estas luchas ${ }^{49}$.

Aparte de la lectura crítica de género, actualmente existe una tendencia -por ahora minoritaria pero significativa- sobre el papel que han adquirido las Tecnologías de Información y Comunicación (TIC) y las nuevas dinámicas de socialización mediante plataformas virtuales en los movimientos estudiantiles. Esta aproximación teórica es propia del siglo XXI, debido a la actualidad de estas redes o plataformas sociales en internet, así como las acciones de carácter organizativo que permiten aplicaciones tales como Facebook, Instagram y Twitter en los movimientos estudiantiles $^{50}$. En este contexto, el trabajo de Lázaro Bacallao-Pino hace énfasis directo en estas dinámicas de interacción virtual, que trae consigo la comunicación no-presencial, pero en tiempo real ${ }^{51}$.

Bacallao-Pino explica que la cantidad de seguidores que, sobre la acción de una federación estudiantil universitaria se realiza por medio de su facebook, supera hasta en el doble a la cantidad total de estudiantes ${ }^{52}$.

Este tipo de estudios sobre los movimientos estudiantiles, con enfoque sobre la apropiación del recurso tecnológico virtual, también es foco de atención de otras

2020, http://www.redalyc.org/articulo.oa?id=88435814008. El texto es erudito en el manejo de las teóricas, postulados y discusiones desde el feminismo y los estudios de género; que, al ser denunciantes sobre las formas estructurales en que las mujeres son delegadas en el ejercicio del poder político debido a una supremacía masculina en esta área, evidencia que esto mismo está presente en los movimientos estudiantiles.

${ }^{49}$ Mónica Conteras García, «Género, historia y memoria de los movimientos estudiantiles de México: reflexiones sobre la figura del 'estudiante'», Revista de Estudios de Género, La ventana 42 (2015): 181-219, acceso: 14 de julio de 2020,

http://www.redalyc.org/articulo.oa?id=88446716008. La autora realiza un privilegiado abordaje fundamentado desde las teorías de género y los entrelaza con la producción académica de movimientos estudiantiles mexicanos (con énfasis en las luchas de 1960 y 1970), además de ahondar en epistemología sobre la memoria.

${ }^{50}$ Es importante argumentar que la aplicación de plataformas virtuales para emprender la lucha estudiantil, no opaca algunas de las expresiones típicas de estos como la convocatoria para una marcha, el que existan liderazgos específicos de estudiantes que van al frente en la organización, la necesidad de expresar la pluralidad de colectivos estudiantiles y la necesidad de realizar encuentros personales para llegar a los principales acuerdos de movilización, demandas y organización necesarias en el mantenimiento de una lucha estudiantil.

${ }^{51}$ Lázaro Bacallao-Pino. «Redes sociales, acción colectiva y elecciones: los usos de Facebook por el movimiento estudiantil chileno durante la campaña electoral de 2013», Palabra Clave (2016): 810-837, acceso: 14 de julio de 2020, http://www.redalyc.org/articulo.oa?id=64946476006

52 Además, estudia comparadamente cuáles fueron las expresiones políticas que durante la campaña electoral chilena del 2013 tuvieron dos federaciones de universidades públicas y una universidad privada: la Federación Universitaria de la Universidad de Chile (FEUCH), Federación Universitaria de la Universidad de Santiago de Chile (FEUSACH) y la privada Federación Universitaria de la Pontificia Universidad Católica de Chile (FEUC).

ESPIGA' @(1) (1) Año 20, N. ${ }^{\circ} 40: 24-56$, julio - diciembre 2020 
investigaciones como las de Guadalupe Olivier Téllez y Sergio Tamayo ${ }^{53}$, que aparte de explicar el surgimiento del movimiento estudiantil mexicano \#YoSoy132, en el 2012, explican las formas temporales en los que el facebook se utiliza como herramienta para la exposición de criterios políticos con una capacidad ampliada en la divulgación inmediata de las consignas.

El artículo es resultado de una investigación multidimensional de la movilización juvenil y estudiantil surgida como protesta a los discursos de Enrique Peña Nieto y la política del Partido Revolucionario Institucional (PRI) en el contexto de los comicios del 2012. En este escenario, Olivier y Tamayo explican ${ }^{54}$ :

Llegaron 131 videos de jóvenes que respondieron así: "somos estudiantes $[\ldots]$ no porros, $[\ldots]$ no acarreados $[\ldots]$ nadie nos entrenó para nada" (González, 2013:61-62). El video se publicó el 14 de mayo con el hashtag "\#131 alumnosdelaIbero". A las pocas horas se hizo trending topic a nivel mundial. Se sumaron 125000 twitts que reconocían el valor de los estudiantes de la Ibero de presentarse pública y abiertamente desafiando una posible respuesta represiva por las autoridades. Ese mismo día, a iniciativa de Saúl Alvídrez, estudiante de Derecho y Economía del Instituto Tecnológico y Estudios Superiores de Monterrey (ITESM), se invitó a todos los simpatizantes a sumarse a la causa de los \#131 alumnos de la Ibero, y formar así el \#YoSoy132.

Este aporte académico de Olivier y Tamayo ${ }^{55}$ supera la descripción de los hechos y contribuye con una importante presentación de fuentes que han analizado la relación entre movimientos sociales y redes sociales virtuales. Es en ese aspecto que colocan a este efímero movimiento social con otras acciones similares localizables en el siglo XXI, como: «la Primavera Árabe, de diciembre de 2010; el movimiento de Indignados-15M en España; además del Movimiento Estudiantil Chileno, ambos de mayo de 2011; y el movimiento de los Occupy-Wall Street, en Estados Unidos, de septiembre de $2011 »^{56}$.

En una lógica similar al uso de las plataformas digitales en internet como mecanismos de lucha de los movimientos, en forma de antecedente a estos se ubica el aporte que el historiador salvadoreño Ricardo Antonio Argueta Hernández ${ }^{57}, L a$ Asociación De Estudiantes Universitarios Salvadoreños (AGEUS) a través de la prensa escrita (1927-1961), en el que realiza la importante contribución de

\footnotetext{
${ }^{53}$ Guadalupe Olivier Téllez y Sergio Tamayo, «Tensiones políticas en el proceso de movilización-desmovilización: El movimiento \#YoSoy132», Iztapalapa, Revista de Ciencias Sociales y Humanidades 79 (2015). Acceso: 14 de enero de 2020, http://www.redalyc.org/articulo.oa?id=39348248009

${ }_{54}^{54}$ Guadalupe Olivier y Sergio Tamayo, Tensiones políticas en el proceso..., 140.

${ }^{55}$ Ibíd, 135. Este artículo cuenta con importantes referencias bibliográficas sobre el «papel de los medios y redes cibernéticas en la protesta social», lo cual es una buena referencia para ampliar en este nuevo terreno de la comunicación cibernética como parte de las acciones colectivas.

${ }^{56}$ Ibíd, 133.

${ }^{57}$ Ricardo Antonio Argueta Hernández, La Asociación de Estudiantes de Universitarios Salvadoreños (AGEUS) a través de la prensa escrita (1927-1961), tesis de maestría en Historia, Universidad de Costa Rica, 2006. 
comprender el pensamiento, protestas, consignas y luchas que el movimiento estudiantil realiza desde sus medios de prensa autónomos, que en el caso del estudio de Argueta, logra contraponer los criterios del movimiento estudiantil mediante su periódico boletín Opinión Estudiantil, con las noticias y argumentos de la prensa oficial de El Salvador durante el período de estudio. De esta tesis sobresale el uso de la fuente primaria del boletín de la AGEUS como herramienta metodológica del que se logra apreciar el pensamiento universitario.

Como se ha visto, la teorización de los movimientos estudiantiles ha tenido reflexiones desde las concepciones de generación, legión, género, redes sociales virtuales y prensa, además desde sus elementos constitutivos. Este resulta en un mosaico de aproximaciones conceptuales que dialogan cada una según sus propios encuadres, pero poco entre $s^{158}$. Sin embargo, existen dos corrientes teóricas que de una manera más constante han estado presentes en los estudios sobre movimientos estudiantiles. Estos son los enfoques teóricos de los movimientos sociales, por un lado, y de las acciones colectivas, por el otro, que se analizan a continuación.

\section{Luchas estudiantiles desde las acciones colectivas y los movimientos sociales}

El estudio de las luchas estudiantiles está relacionado con los enfoques de los movimientos sociales y -posteriormente- de las acciones colectivas. Un estudio de este tipo es El movimiento estudiantil y la teoría de los movimientos sociales, del investigador mexicano José María Aranda Sánchez ${ }^{59}$, quien realiza un importante repaso sobre los acercamientos teóricos de los movimientos sociales para constatar cómo estos colocan bases para el análisis de los movimientos estudiantiles.

Aranda $^{60}$ recupera los aportes de teorías de movimientos sociales que se han catalogado -según sus posturas analíticas e históricas- como clásicos y nuevos movimientos sociales, que surgen, en ambos casos, producto de las acciones que se emprenden desde la sociedad civil para impulsar cambios y expresar abiertamente el descontento sobre crisis políticas, económicas o culturales.

Según Aranda ${ }^{61}$, la lectura clásica de los movimientos sociales incluye el análisis desde tres enfoques centrales: el hecho de que estos surgen como un proceso de conducta colectiva a la que se adhieren los sujetos como parte de un proceso racional

\footnotetext{
${ }^{58}$ Es importante aclarar que la poca mención a investigaciones desde América Central, se debe a que la gran mayoría de estas incluye pocas variantes epistemológicas incorporadas en los estudios que surgen de las realidades sociopolíticas de Guatemala, Honduras, El Salvador, Nicaragua, Costa Rica y Panamá, se han realizado, priorizando producciones académicas en las que las acciones estudiantiles, sin integrar más variantes teóricas o metodológicas, se reseñan según sus hechos históricos. Sin duda, esta historia regional de movimientos estudiantiles en América Central es de suma importancia y, por ello, desde el Centro Agenda Joven se decidió publicar dos artículos que permitan explicar, década por década y según cada contexto nacional, la historia que, entre 1918-2018, han librado los movimientos estudiantiles de esta región inmediata. Para consultas, visitar el portal web de Agenda Joven.

59 José Aranda Sánchez, «El Movimiento Estudiantil y la Teoría de los Movimientos Sociales», Convergencia Revista de Ciencias Sociales, 21 (2000), acceso: 14 de julio de 2020. http://revistacoatepec.uaemex.mx/index.php/convergencia/article/view/1856

${ }^{60}$ José Aranda Sánchez, El Movimiento Estudiantil y la Teoría..., 225.

${ }^{61}$ Ibíd., 227-229. 
que les lleva a incorporarse en los colectivos de protesta social ${ }^{62}$. Seguido por la teoría de la movilización de recursos y su enfoque de oportunidades políticas ${ }^{63}$, hace alusión a los contextos precisos por los cuales surgen los movimientos sociales en el marco de formas innovadores de participación política que ejercen como grupos de presión.

Desligado de este abordaje epistemológico Aranda Sánchez retoma las principales características en las que se recoge el análisis de los nuevos movimientos sociales $(\mathrm{NMS})^{64} \mathrm{y}$, con ello, interpretar de esta manera a los movimientos estudiantiles, con lo que Aranda ${ }^{65}$ explica las siguientes características:

-Una expresión de nuevos valores que critican la ética productiva de la modernidad, buscando nuevas relaciones con la naturaleza.

-Debido a sus formas de acción y organización, relacionada con formas no convencionales de acción en los que «preferían organizaciones de pequeña escala y descentralizadas, anti-jerárquicas y que favorecieran la democracia directa» ${ }^{66}$.

-Una tendiente constitución desde sectores de las clases medias «en particular, entre aquellos dedicados a los servicios sociales y culturales» ${ }^{67}$.

-También se encuentra el elemento de las nuevas aspiraciones que vendrían a ser expresiones de lucha social en el marco de la ampliación de servicios sociales que generaron los diferentes Estados de bienestar.

De esta manera, Aranda argumenta que los movimientos estudiantiles universitarios pueden ser vistos como movimientos sociales en el tanto son una parte peculiar en el entramado de los movimientos juveniles.

Otra de las cualidades de los movimientos estudiantiles como movimientos sociales, es su capacidad de configurar y defender una propia identidad como colectiva social, además de proclamarse desde posturas ideológicas. Esta construcción de identidad se construye en la lucha misma, así la práctica de realizar asambleas estudiantiles ayuda a la cohesión del movimiento y la comunidad estudiantil que se va articulando alrededor de las demandas que persiguen. Al respecto, Aranda explica ${ }^{68}$ :

La identidad se define en la lucha, en el conjunto de acciones y movilizaciones, a través de las cuales se logra la integración social, la cohesión y la resistencia, por lo

\footnotetext{
${ }^{62}$ Ibíd., 227. Sobre este argumento, Aranda referencia a los siguientes exponentes teóricos: «(...) varios sociólogos de la Escuela de Chicago, como Ralph Turner y Lewis Killian; Talcott Parsons y su estructural funcionalismo y, sobre todo, Neil Smelser, quien formalizó y clarificó el planteamiento en su conocida obra Theory of collective behavior (1962)».

${ }^{63}$ Entre los principales exponentes que señala el autor, están: Charles Tilly, Mayer Zald, Timoty Garton Ash y Herbert Kitschelt.

${ }^{64}$ El autor identifica como principales teóricos a Jürgen Habermas, Clauss Offe, Sidney Tarrow, Alain Touraine, Alberto Melucci y Jean Cohen.

${ }^{65}$ José Aranda Sánchez, «El Movimiento Estudiantil y la Teoría de los Movimientos Sociales», Convergencia Revista de Ciencias Sociales, 21 (2000), 230-231.

${ }^{66}$ José Aranda, El Movimiento Estudiantil y la Teoría..., 232.

${ }^{67}$ Ibíd.

${ }^{68}$ Ibíd., 245.

ESPIGA: @® Año 20, N.․ 40: 24-56, julio - diciembre 2020 
que aparecen diversas y novedosas formas de solidaridad y actitudes asociativas acordes a las condiciones de la lucha.

En otro estudio similar al anterior, el investigador venezolano Roberto López Sánchez ${ }^{69}$, en Fundamentos teóricos para el estudio de los movimientos estudiantiles en Venezuela, realiza un análisis desde la teoría de los movimientos sociales, la teoría de la movilización de recursos y la teoría de la creación de identidades colectivas. En este aspecto, López se apoya desde el estudio de las acciones colectivas, en el tanto los grupos sociales actúan desde los recursos y oportunidades que se construyen conforme a objetivos comunes de los grupos que protestan ${ }^{70}$.

Roberto López ${ }^{71}$ enfatiza en la importancia de la construcción identitaria de los movimientos estudiantiles en cuanto a agrupaciones que generan sentidos de pertenencia e identidad para sus integrantes. Este aspecto, según el autor, implica un importante papel para la exposición del carisma de sus líderes, así como las expresiones políticas que les diferencia de los demás actores sociales y políticos que le rodean.

Similar a estos estudios, se encuentra el análisis de María Isabel Domínguez ${ }^{72}$, quien argumenta que las poblaciones jóvenes conforman una parte importante de los movimientos sociales, tanto de sus propias estructuras -como los movimientos estudiantiles-, como de los que no les son exclusivos. Su argumento se basa en la cualidad generacional que constituyen los diferentes momentos históricos de las juventudes que se agrupan como generación y hacen de esta conexión, una fuerza política y social. Para esto, la autora conceptualiza como generación ${ }^{73}$ :

Como el conjunto histórico-concreto de personas, próximas por la edad y socializadas en un determinado momento de la evolución de la sociedad, lo que condiciona una actividad social común en etapas claves de formación de la personalidad que da lugar a rasgos estructurales y subjetivos similares que la dotan de una fisonomía propia.

El análisis de la autora se centra en la figura de las personas jóvenes, sin hacer exclusivos los análisis de los movimientos estudiantiles; sin embargo, en esta línea de análisis, ratifica el sondeo constante de alternativas que las personas jóvenes buscan al movilizarse políticamente, siendo esta una de las cualidades centrales de los movimientos estudiantiles que suelen ser «capaces de conquistar espacios públicos y articularse con lo político» ${ }^{74}$.

Similar al estudio de María Isabel Domínguez, en el que las personas jóvenes son parte activa de los movimientos sociales debido a su dinamismo y conformación

\footnotetext{
${ }^{69}$ Roberto López Sánchez, «Fundamentos teóricos para el estudio de los movimientos estudiantiles en Venezuela», Espacio abierto, 14 (4) (2005), acceso: 14 de julio de 2020, http://www.redalyc.org/articulo.oa?id=12214405

${ }^{70}$ Roberto López Sánchez, Fundamentos teóricos..., 594. En este estudio, López referencia estos planteamientos de autores como John McCarthy, Mayer Zald, Doug McAdam (1996)

y Sidney Tarrow (1997).

${ }^{71}$ Ibíd., 606.

${ }^{72}$ María Isabel Domínguez, «Los movimientos sociales y la acción juvenil: apuntes para un debate», Sociedade e Estado 21 (2006): 67-83, acceso: 14 de julio de 2020,

http://www.redalyc.org/articulo.oa?id=3399308830052006

${ }^{73}$ Ibíd., 69.

${ }^{74}$ Ibíd., 73.

ESPIGA' @(1) (1) Año 20, N. ${ }^{\circ}$ 40: 24-56, julio - diciembre 2020 
como cuerpo político, también se encuentra el estudio de Aquiles Chihu Amparán ${ }^{75}$, que hace un análisis cultural de los movimientos sociales. En este estudio ${ }^{76}$, se plantea que las protestas surgen cuando existe un común posicionamiento en la identificación de un sentido de injusticia, siendo esta el punto de partida para la acción colectiva. Esta injusticia, en el contexto de los movimientos estudiantiles, se acoge con el sentir generacional sobre la lectura del tiempo y sociedad histórica en la que se vive.

Finalmente, con este acercamiento entre movimientos estudiantiles con las teorías de los movimientos sociales y las acciones colectivas, se refuerza el argumento que justifica la particularización de los movimientos estudiantiles como expresiones propias de la acción política juvenil.

\section{Conclusiones}

El amplio repaso que se ha hecho sobre los abordajes teóricos en investigaciones sobre movimientos estudiantiles latinoamericanos, permite apreciar lo continuo del análisis, reflexión y documentación de estos, en la que prevalece una escritura descriptiva e histórica de las grandes acciones de protesta desde las universidades, siendo las luchas, en sí mismas, los elementos que mayor estudio han tenido. No obstante, las investigaciones con enfoques y métodos específicos sobre alguna cualidad de los movimientos estudiantiles, ha venido en crecimiento conceptual desde la academia, razón por la cual en este artículo fueron presentados según sus temáticas particulares.

El conjunto de estos estudios muestran un impacto transformador desde los movimientos estudiantiles desde contextos puntuales en los países del continente, a la vez que muestran la cercanía que existe entre movimientos estudiantiles y procesos de lucha política desde tendencias críticas a las sociedades dominantes, conservadoras, patriarcales, eclesiásticas y capitalistas; en los cuales la acción juvenil universitaria ha sido protagonista en diferentes contextos sociopolíticos que engloban cien años de lucha y dados desde diferentes repertorios de acción social; esto evidencia lo profundo y diverso de las luchas estudiantiles, tanto por sus proclamas, como desde los énfasis metodológicos a partir de los cuales se han analizado en este siglo (1918-2018).

En ese trayecto continuo, las generaciones universitarias de la primera mitad del siglo XX construyeron movimientos estudiantiles comprometidos con sus causas gremiales y a favor de los sectores sociales empobrecidos, al punto de consagrarse como uno de los principales grupos de oposición a gobiernos autoritarios de las clases dominantes. Esto provoca que el estudiantado se mostrara como actor sociopolítico con importante influencia en los contextos nacionales.

En esa composición como movimientos sociales y constantes actores políticos, las luchas estudiantiles tuvieron un mayor impacto en las décadas de 1960 y 1970,

${ }^{75}$ Aquiles Chihu Amparán y Alejandro López Gallegos, «La construcción de la identidad colectiva en Alberto Melucci», Polis 3 (2007): 125-159, acceso: 14 de julio de 2020,

http://www.redalyc.org/articulo.oa?id=305026734005

${ }^{76}$ Ibíd.

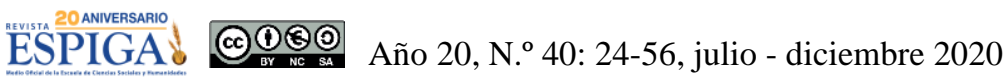


cuando impulsaron procesos de transformación cultural que abrieron camino hacia sociedades más democráticas.

Así, las acciones de lucha estudiantil fueron configurando contextos de persecución, secuestro y muerte de personas universitarias, quienes fueron mostrándose como agentes políticos opuestos a gobiernos autoritarios que, en ocasiones, no titubearon en incriminarles y perseguirles. Sin embargo, esta situación mermó los movimientos estudiantiles, que continuaron protagonizando importantes hechos de su propia historia con una activa participación en la sociopolítica en la segunda mitad del siglo $\mathrm{XX}$. Es en este contexto que se han contrapuesto varios esfuerzos académicos latinoamericanos, orientados a documentar, analizar y explicar sobre el quehacer universitario, enfatizado en cómo se han estudiado sus luchas sociales y políticas.

En última instancia, es el estudiantado, en cada generación, quien protagoniza sus mismos proyectos políticos, los cuales, identificándose con causas propias y ajenas, se llenan de una convicción de cambio a las sociedades modernas del continente. $\mathrm{Su}$ interés ha estado asociado a profundizar las condiciones en que se presenta la autonomía universitaria como un espacio ganado y defendido por varias generaciones estudiantiles que han venido ejerciendo una propia expresión política de lucha por la transformación social dirigida hacia la justicia, igualdad, equidad, democracia y libertad.

Nota del editor. En la página 51 puede revisar el anexo: «Compilaciones de luchas estudiantiles en América Latina».

\section{Formato de citación según APA}

Gutiérrez-Slon, J. A. (2020). Movimientos estudiantiles en cuestión: 100 años de lucha, 100 años de estudio. Revista Espiga, 20 (40), páginas 24-56

\section{Formato de citación según Chicago-Deusto}

Gutiérrez-Slon, Juan Antonio. «Movimientos estudiantiles en cuestión: 100 años de lucha, 100 años de estudio». Revista Espiga 20, n. ${ }^{\circ} 40$ (juliodiciembre, 2020): páginas 24-56

\section{Fuentes consultadas}

Acevedo Tarazona, Álvaro. «Modernización universitaria y protesta estudiantil en Colombia: el caso de la Universidad Industrial de Santander (19531977)». Anuario de Historia Regional y de las Fronteras 17 (2) (2012): 371-399. Acceso: 14 de julio de 2020. http://www.redalyc.org/articulo.oa?id=407539692012

Álvaro Acevedo Tarazona. «El movimiento estudiantil como objeto de estudio en la historiografía colombiana y continental: notas para un balance y una agenda de investigación». Historia y Memoria, Núm. 3, 2011. Acceso: 22 de julio de 2020. https://revistas.uptc.edu.co/index.php/historia_memoria/article/view/799 
Argueta Hernández, Ricardo Antonio. La Asociación de Estudiantes de Universitarios Salvadoreños (AGEUS) a través de la prensa escrita (19271961). Tesis de Maestría en Historia. Universidad de Costa Rica, 2006.

Aranda Sánchez, José. «El Movimiento Estudiantil y la Teoría de los Movimientos Sociales». Convergencia Revista de Ciencias Sociales, 21 (2000): 225-250. Acceso: 14 de julio de 2020.

http://revistacoatepec.uaemex.mx/index.php/convergencia/article/view/1856

Bacallao-Pino, Lázaro. «Redes sociales, acción colectiva y elecciones: los usos de Facebook por el movimiento estudiantil chileno durante la campaña electoral de 2013», Palabra Clave (2016): 810-837. Acceso: 14 de julio de 2020. http://www.redalyc.org/articulo.oa?id=64946476006.

Balardini, Sergio. «Mutacions del moviment juvenil a l'Argentina: Córdoba, 'cordobazo' i després». En Joves entre dos mons. Movimients juvenils a Europa i a América Llatina. Barcelona: Generalitat de Catalunya/ Universitat de Lleida, 2000.

Bárbara y Jhon Ehrenreich. Itinerario de la Rebelión Estudiantil. Traducción de Javier Guerrero. México: Editorial Nuestro Tiempo S.A., 1969.

Bernal, Salvador y Andrés Garrido. Diálogos entre universitarios. Madrid: Artes Gráficas Ibarra S.A., 1969.

Bordagaray, María Eugenia. «Anarquismo y movimiento universitario en Argentina, 1935-1950». Revista CS 9 (2012): 309-332. Acceso: 14 de julio de 2020. http://www.redalyc.org/articulo.oa?id=476348372010

Bonavena, Pablo y Mariano Millán (editores). Los 68 latinoamericanos. Buenos Aires: CLACSO, 2018.

Brunner, José Joaquín. «El movimiento estudiantil». En La Juventud Universitaria en América Latina. Juan Carlos Tedesco, Hans Blumenthal y Orlando Albornoz, 279-290. Caracas: Centro Regional para la Educación Superior en América Latina y el Caribe, 1986.

Califa, Juan Sebastián. «El movimiento estudiantil reformista contra el Plan cafade. Cientificismo, imperialismo, reestructuración universitaria y lucha política (1959-1960)». Redes 32 (2011): 61-184. Acceso: 14 de julio de 2020. http://www.redalyc.org/articulo.oa?id=90722371006

Cástor, Susy (s.f.). «El Movimiento universitario en el Caribe». En Proyecto Movimientos Sociales en el Caribe Centro de Estudios Latinoamericanos. UNAM (versión preliminar).

Chihu Amparán, Aquiles y Alejandro López Gallegos. «La construcción de la identidad colectiva en Alberto Melucci». Polis 3 (2007): 125-159. 
Cohn-Bendit, Sauvageot. La rebelión estudiantil. México: Serie Popular ERA, 1969.

Contreras García, Mónica. «Género, historia y memoria de los movimientos estudiantiles de México: reflexiones sobre la figura del 'estudiante'». Revista de Estudios de Género. La ventana 42 (2015): 181-219. Acceso: 14 de julio de 2020. http://www.redalyc.org/articulo.oa?id=88446716008

Cruz Rodríguez, Edwin. «La reforma de la educación superior y las protestas estudiantiles en Colombia». Postdata 18 (2013): 51-71. Acceso: 14 de julio de 2020. www.scielo.org.ar/scielo.php?pid=S1851$96012013000100002 \&$ script=sci_arttext\&tlng=en

Cúneo, Dardo (compilador). La reforma universitaria (1918-1930). Caracas: Biblioteca Ayacucho, 1978.

Del Castillo Troncoso, Alberto. «Daniel Luna Cárdenas y Paulina Martínez Figueroa (investigación visual), La academia de San Carlos en el movimiento estudiantil de 1968, ENAP-UNAM, México, 74 (2009): 172175». Secuencia. Revista de historia y ciencias sociales (2009). Acceso: 14 de julio de 2020. http://www.redalyc.org/articulo.oa?id=319127432008

Domínguez, María Isabel. «Los movimientos sociales y la acción juvenil: apuntes para un debate». Sociedade e Estado 21 (2006): 67-83. Acceso: 14 de julio de 2020. http://www.redalyc.org/articulo.oa?id=339930883005

Fernández Poncela, Anna María. «Movimientos y sentimientos». Revista Latinoamericana de Estudios sobre Cuerpos, Emociones y Sociedad, 5, (13) (2013): 35-50. Universidad Nacional de Córdoba. Córdoba, Argentina.

Feuer, Lewis. Los movimientos estudiantiles. Las revoluciones nacionales y sociales en Europa y el Tercer Mundo. Buenos Aires: Paidós, 1969.

Fuentes, Carlos; Sastre, Jean Paul y otros. La revolución estudiantil. San José: Editorial Universitaria Centroamericana (EDUCA) con autorización del Semanario Marcha de Montevideo. San José, Costa Rica. Ciudad Universitaria Rodrigo Facio, 1971.

Gentili, Pablo y Emir Sader (compiladores). OSAL, Observatorio social de América Latina (año XIII no. 31 mayo 2012). Buenos Aires: CLACSO, 2012.

Yanko González Cangas. «Qué los viejos se vayan a casa. Juventud y vanguardias en Chile y América Latina», en Movimientos Juveniles. De la globalización a la antiglobalización, ed. por María del Carmen Costa González, Joan Saura y Carles Feixa Pàmpols (coords.) Barcelona: Ariel, 2002. 
Gutiérrez-Slon, Juan Antonio. Mundos juveniles en movimientos estudiantiles: historia, vida cotidiana y acciones de lucha en la FEUNA, 1973-2012. Tesis de maestría en Historia. Universidad de Costa Rica, 2015.

Pedro Ibarra y Noemi Bergantiños. «Movimientos estudiantiles: de mayo del 68 a la actualidad. Sobre las experiencias utópicas de un movimiento peculiar», en Movimientos estudiantiles: resistir, imaginar, crear en la universidad, ed. por Xabier Albizu Landa, Joseba Fernández González y Jon Bernat Zubiri Rey. 2-18. Barcelona: Gakoa, 2008.

Kandel Victoria. «Participación estudiantil y gobierno universitario: nuevos actores-viejas estructuras». Tesis de maestría en Ciencias Sociales, con Orientación en Educación, Buenos Aires: FLACSO, 2005. Acceso: 22 de julio de 2020. http://propuestaeducativa.flacso.org.ar/wpcontent/uploads/2019/12/resen\%CC\%83a_tesis_Kandel_PE28.pdf

. «Gobierno universitario y participación estudiantil.

Consideraciones sobre el cogobierno y la democracia en la universidad pública». Propuesta Educativa 34 (2010): 97-103. Acceso: 14 de julio de 2020. http://www.redalyc.org/articulo.oa?id=403041705010

Kandel, Victoria y Cecilia Cortés. «Reflexiones en torno a las nuevas formas de participación estudiantil en la vida política de la universidad». Fundamentos en humanidades 3 (5-6) (2002): 23-34.

López Sánchez, Roberto. «Fundamentos teóricos para el estudio de los movimientos estudiantiles en Venezuela». Espacio abierto, 14 (4) (2005): 589-607.

Mangiantini, Martín. «PRT-La verdad y el movimiento estudiantil argentino. Hacia un análisis de las estrategias de inserción y de las tensiones existentes (1968-1972)». Revista Izquierdas 23 (2015): 81-101. Acceso: 14 de julio de 2020. http://www.redalyc.org/articulo.oa?id=360135258005

Marcuse, Herbert. La rebelión de los estudiantes. Buenos Aires: Paidós, 1969. . El fin de la utopía. México: Siglo Veintiuno Editores S.A., 1971.

Markarian, Vania. «Sobre viejas y nuevas izquierdas. Los jóvenes comunistas uruguayos y el movimiento estudiantil de 1968». Secuencia. Revista de historia y ciencias sociales 81 (2011): 159-186. Acceso: 14 de julio de 2020. http://www.redalyc.org/articulo.oa?id=319127440007

Marsiske, Renate (comp.). Movimientos Estudiantiles en la historia de América Latina. Vol. I y II. México: UNAM, Centro de Estudios sobre la Universidad, Plaza y Valdés editores, 1999.

. Movimientos Estudiantiles en la historia de América Latina. Vol. III. México: UNAM, Centro de Estudios sobre la Universidad, Plaza y Valdés editores, 2006. 
. Movimientos estudiantiles en la historia de América

Latina / Vol IV. México: (Colección Historia de la Educación), Instituto de Investigaciones sobre la Universidad y la Educación, UNAM, D.F., 2015.

Martínez, Orlando Moreno. «El paro estudiantil de mayo de 1938». Anuario Colombiano de Historia Social y de la Cultura 36 (2) (2009): 41-63.

Melucci, Alberto. «Asumir un compromiso: identidad y movilización en los movimientos sociales». Revista Zona Abierta 69 (1994).

Michelena, Héctor y Sonntag, Rudolf. Universidad, dependencia y revolución. México, Siglo XXI, 1984.

Montaño, Eugenia Allier. «Alberto del Castillo. Ensayo sobre el movimiento estudiantil de 1968. La fotografía y la construcción de un imaginario». México: Universidad Nacional Autónoma de México-Instituto de Investigaciones sobre la Universidad y la Educación/Instituto Mora, 2012. Revista Mexicana de Sociología 76 (4) (2014): 665-677.

Negrín Fajardo, Olegario.«El movimiento estudiantil cubano en la segunda mitad del siglo XIX». En La Influencia Pedagógica Española en Iberoamérica:

Estudios Sobre Historia de la Educación Contemporánea. España: Aula Abierta, 36(12). Universidad Nacional de Educación a Distancia, Series, 1999.

Nashik, Antonio Gómez. «1956-1966: huelgas estudiantiles en la Universidad de Michoacán». Universidades 61 (2014): 19-36. Acceso: 14 de julio de 2020. http://www.redalyc.org/articulo.oa?id=37333039004

Olivier Téllez, Guadalupe, y Sergio Tamayo. «Tensiones políticas en el proceso de movilización-desmovilización: El movimiento \#YoSoy132». Iztapalapa, Revista de Ciencias Sociales y Humanidades 79 (2015): 131-170. Acceso: 14 de julio de 2020. http://www.redalyc.org/articulo.oa?id=39348248009

Portantiero, Juan Carlos. Estudiantes y política en América Latina. El proceso de la reforma universitaria (1918-1938). México: Siglo Veintiuno Editores, 1978.

Posada Martínez, Jorge Eliécer y Diego Fernando Barragan Giraldo. «Juventud y multitud: Aproximaciones para abordar los movimientos juveniles». Tabula Rasa 9 (2008): 353-368. Acceso: 14 de julio de 2020. http://www.redalyc.org/articulo.oa?id=39600917

Ramírez, Ramón. El movimiento estudiantil de México. Julio-diciembre de 1968 (tomos I y II). Colección Problemas de México. México: Ediciones Era, 1969.

Roco Lobos, Micaela. «La influencia de las organizaciones políticas universitarias en la formación de élites políticas en Chile: el caso de las federaciones de estudiantes de la Universidad de Chile y Universidad Católica 1984-2005». 
Política 54 (2) (2014): 157-183. Acceso: 14 de julio de 2020.

http://www.redalyc.org/articulo.oa?id=64537763006

Silva Michelena, José Agustín. «La participación estudiantil en las actividades políticas», en Juan Carlos Tedesco y Hans R. Blumenthal (compiladores). La Juventud Universitaria en América Latina. Caracas: Centro Regional para la Educación Superior en América Latina y el Caribe: Instituto Latinoamericano de Investigaciones Sociales, 1986.

Solari, Aldo (ed.). Estudiantes y política en América Latina. Caracas: Monte Ávila Editores, 1967.

Tedesco, Juan Carlos, Hans Blumenthal y Orlando Albornoz. La Juventud universitaria en América Latina. Caracas: Centro Regional para la Educación Superior en América Latina y el Caribe, 1986.

Tirado Villegas, Gloria Arminda. «Puebla 1961. Género y movimiento estudiantil». Revista de Estudios de Género. La ventana 5 (39) (2014): 179-207. Acceso: 14 de julio de 2020. http://www.redalyc.org/articulo.oa?id=88435814008

Vázquez, Adolfo Sánchez. «El movimiento del 68. Testimonio y Reflexiones». Sociológica 13 (38) (1998): 145-152.

Villarreal, Juan. La reforma universitaria. Caracas: Biblioteca Ayacucho, 1971. 
Anexo

\section{Compilaciones de luchas estudiantiles en América Latina}

La historia de los movimientos estudiantiles en América Latina tiene muchas expresiones, según las luchas que las personas universitarias han realizado en cada uno de sus países y, en ocasiones, los esfuerzos académicos y de investigación han optado por la compilación de movimientos estudiantiles para un análisis plural de estos. De ahí que el trabajo compilador de Renate Marsiske Schulte, investigadora de la Universidad Nacional Autónoma de México (UNAM), sobre la historia de los movimientos estudiantiles en América Latina, se muestra como uno de los principales compendios sobre esta materia, que, aparte de amplio en contenido, muestra una pluralidad de acciones estudiantiles que integran cuatro tomos, que se presenta seguidamente.

Cuadro 1. Lista de artículos que integran el volumen I de las compilaciones realizadas por Renate Marsiske

\begin{tabular}{|c|c|c|}
\hline Autor / Autora & Artículo & País / Región \\
\hline Renate Marsiske & Presentación & México \\
\hline Leticia Pérez Puente & $\begin{array}{l}\text { Una revuelta universitaria en } 1671 \text { ¿Intereses } \\
\text { estudiantiles o pugnas de autoridades? }\end{array}$ & México \\
\hline Diana Soto Arango & $\begin{array}{l}\text { El movimiento de estudiantes y catedráticos } \\
\text { en Santa Fe de Bogotá a fines del siglo XVIII }\end{array}$ & Colombia \\
\hline $\begin{array}{l}\text { María de Lourdes } \\
\text { Alvarado }\end{array}$ & $\begin{array}{l}\text { La universidad libre: primer movimiento } \\
\text { estudiantil del México independiente }\end{array}$ & México \\
\hline $\begin{array}{l}\text { Cristina Vera de } \\
\text { Flachs }\end{array}$ & $\begin{array}{l}\text { Antecedentes del movimiento universitario } \\
\text { de } 1918 \text { en Córdoba: los primeros profesores } \\
\text { de la Facultad de Ciencias Físico- } \\
\text { Matemáticas }\end{array}$ & Argentina \\
\hline Olegario Negrín & $\begin{array}{l}\text { El movimiento estudiantil cubano en la } \\
\text { segunda mitad del siglo XIX }\end{array}$ & Cuba \\
\hline Renate Marsiske & $\begin{array}{l}\text { Clases medias, universidades y movimientos } \\
\text { estudiantiles en América Latina, 1900-1930 }\end{array}$ & América Latina \\
\hline Mauricio Archila & $\begin{array}{l}\text { Entre la academia y la política: el } \\
\text { movimiento estudiantil en Colombia, } 1920 \text { - } \\
1974\end{array}$ & Colombia \\
\hline Deise Mancebo & $\begin{array}{l}\text { Universidad del Estado de Río de Janeiro: } \\
\text { resistencia estudiantil y reacción } \\
\text { universitaria, 1950-1978 }\end{array}$ & Brasil \\
\hline
\end{tabular}




\begin{tabular}{|l|l|c|}
\hline Gilberto Castañeda & $\begin{array}{l}\text { Luchas estudiantiles en la Facultad de } \\
\text { Arquitectura de la Universidad San Carlos de } \\
\text { Guatemala, 1954-1980 }\end{array}$ & Guatemala \\
\hline
\end{tabular}

Marsiske, Renate (comp.). Movimientos estudiantiles en la historia de América Latina. Vol. I. México: Centro de Estudios sobre la UNAM, Plaza y Valdés

editores, 1999.

Cuadro 2. Lista de artículos en el volumen II de las compilaciones realizadas por Renate Marsiske

\begin{tabular}{|l|l|c|}
\hline \multicolumn{1}{|c|}{ Autor / Autora } & \multicolumn{1}{|c|}{ Artículo } & País / Región \\
\hline Renate Marsiske & Presentación & México \\
\hline Leonardo Carvajal & $\begin{array}{l}\text { Estudiantes universitarios y luchas político- } \\
\text { sociales en Venezuela (1908-1919) }\end{array}$ & Venezuela \\
\hline Marcelo Caruso & $\begin{array}{l}\text { La amante esquiva: comunismo y } \\
\text { reformismo universitario en Argentina } \\
(1918-1966) \text { Una introducción }\end{array}$ & Argentina \\
\hline Mónica Rein & $\begin{array}{l}\text { Represión versus rebelión: universidades } \\
\text { argentinas bajo el peronismo, 1943-1955 }\end{array}$ & Argentina \\
\hline Fernando Pedrosa & $\begin{array}{l}\text { La universidad y los estudiantes frente a la } \\
\text { dictadura militar }\end{array}$ & Argentina \\
\hline Marcela A. Pronko & $\begin{array}{l}\text { Procesos institucionales y estructuración del } \\
\text { movimiento estudiantil. Universidad de } \\
\text { Luján (1979-1990) }\end{array}$ & Argentina \\
\hline
\end{tabular}

Marsiske, Renate (comp.). Movimientos estudiantiles en la historia de América Latina. Vol. II. México: Centro de Estudios sobre la UNAM, Colección Historia de la educación: Serie mayor, 1999. 
Cuadro 3. Lista de artículos en el volumen III de las compilaciones realizadas por Renate Marsiske

\begin{tabular}{|c|c|c|}
\hline Autor / Autora & Artículo & $\begin{array}{l}\text { País / } \\
\text { Región }\end{array}$ \\
\hline Renate Marsiske & Presentación & México \\
\hline $\begin{array}{l}\text { Cristina Vera de } \\
\text { Flachs }\end{array}$ & $\begin{array}{l}\text { Reformas, contrarreformas y movimientos } \\
\text { estudiantiles en la Universidad de Córdoba } \\
(1870-1936)\end{array}$ & Argentina \\
\hline Hugo E. Biagini & $\begin{array}{l}\text { Redes estudiantiles en el Cono Sur (1900- } \\
\text { 1925) }\end{array}$ & $\begin{array}{l}\text { América } \\
\text { del Sur }\end{array}$ \\
\hline $\begin{array}{l}\text { Yazmín Cuevas y } \\
\text { Guadalupe Olivier }\end{array}$ & $\begin{array}{l}\text { Julio Antonio Mella: de líder universitario a } \\
\text { activista social }\end{array}$ & Cuba \\
\hline Renate Marsiske & $\begin{array}{l}\text { Antecedentes del movimiento estudiantil de } \\
1929 \text { en la Universidad de México: } \\
\text { actividades y organización estudiantil }\end{array}$ & México \\
\hline Fabio Moraga Valle & $\begin{array}{l}\text { Crisis y recomposición del movimiento } \\
\text { estudiantil chileno (1990-2001) }\end{array}$ & Chile \\
\hline $\begin{array}{l}\text { Humberto Ruiz } \\
\text { Calderón, y Leomar } \\
\text { Niño G. }\end{array}$ & Los azules se desnudan ante el PLES & Argentina \\
\hline Hugo E. Biagini & $\begin{array}{l}\text { Juventud e identidad: de la reforma } \\
\text { universitaria al posmodernismo }\end{array}$ & Argentina \\
\hline Hugo E. Biagini & Marcuse y la generación de la protesta & $\begin{array}{l}\text { Estados } \\
\text { Unidos y } \\
\text { América } \\
\text { Latina }\end{array}$ \\
\hline
\end{tabular}

Marsiske, Renate (comp.). Movimientos estudiantiles en la historia de América Latina. Vol III. México: Centro de Estudios sobre la Universidad, UNAM, Plaza y Valdés Editores, 2006. 
Cuadro 4. Artículos en el volumen IV de las compilaciones realizadas por Renate Marsiske

\begin{tabular}{|c|c|c|}
\hline Autor / Autora & Artículo & $\begin{array}{l}\text { País / } \\
\text { Región }\end{array}$ \\
\hline Renate Marsiske & Presentación & México \\
\hline Ellen Spielmann & Introducción & Brasil \\
\hline Renate Marsiske & $\begin{array}{l}\text { Los estudiantes de la reforma universitaria } \\
\text { en América Latina: ¿Una generación? }\end{array}$ & $\begin{array}{l}\text { América } \\
\text { Latina }\end{array}$ \\
\hline $\begin{array}{l}\text { Miguel Ángel } \\
\text { Gutiérrez López }\end{array}$ & $\begin{array}{l}\text { Líderes estudiantiles socialistas en } \\
\text { Michoacán. Breve itinerario político (1928- } \\
\text { 1963) }\end{array}$ & México \\
\hline $\begin{array}{l}\text { Octávio Luiz } \\
\text { Machado }\end{array}$ & Un siglo de movimiento estudiantil en Brasil & Brasil \\
\hline Ellen Spielmann & $\begin{array}{l}\text { Vidas y milagros de los líderes estudiantiles } \\
\text { brasileños del 68: una aproximación } \\
\text { microhistórica a José Dirceu y Prova de } \\
\text { Fogo }\end{array}$ & Brasil \\
\hline $\begin{array}{l}\text { Álvaro Acevedo } \\
\text { Tarazona }\end{array}$ & $\begin{array}{l}\text { Memorias e historia del movimiento } \\
\text { estudiantil en Colombia (1968) }\end{array}$ & Colombia \\
\hline Jaime M. Pensado & $\begin{array}{l}\text { El movimiento politécnico de 1956: la } \\
\text { primera revuelta estudiantil en México de } \\
\text { los sesenta }\end{array}$ & México \\
\hline Pablo Toro Blanco & $\begin{array}{l}\text { La vida de los otros: la FECECH y su } \\
\text { conflictiva relación con el movimiento } \\
\text { estudiantil en la Universidad de Chile } \\
(1978-1984)\end{array}$ & Chile \\
\hline $\begin{array}{l}\text { María Cristina Vera } \\
\text { de Flachs }\end{array}$ & $\begin{array}{l}\text { Escarceos estudiantiles en época de } \\
\text { dictadura, Argentina (1976-1981) }\end{array}$ & Argentina \\
\hline $\begin{array}{l}\text { Sebastián Garrido de } \\
\text { Sierra }\end{array}$ & $\begin{array}{l}\text { Masas críticas y redes sociales: una } \\
\text { explicación microestructural del surgimiento } \\
\text { de cuatro movimientos estudiantiles en la } \\
\text { UNAM (1986-2000) }\end{array}$ & México \\
\hline
\end{tabular}

Marsiske, Renate (comp.). Movimientos estudiantiles en la historia de América Latina. Vol IV. México: Instituto de Investigaciones sobre la Universidad y la Educación, UNAM, Colección Historia de la Educación, 2015. 
Por otro lado, y en otro esfuerzo de compilación sobre movilizaciones estudiantiles en América Latina, se encuentra el trabajo coordinado por el uruguayo Aldo Solari, quien, en 1968 había realizado el esfuerzo de compilación de estudios sobre los movimientos estudiantiles en América Latina.

Cuadro 5. Artículos incluidos en la compilación sobre movimientos estudiantiles realizada por Aldo Solari en 1968

\begin{tabular}{|l|l|c|}
\hline \multicolumn{1}{|c|}{ Autor / Autora } & \multicolumn{1}{|c|}{ Artículo } & $\begin{array}{c}\text { País / } \\
\text { Región }\end{array}$ \\
\hline Aldo Solari & Introducción & Uruguay \\
\hline Jean Labbens & $\begin{array}{l}\text { Las universidades latinoamericanas y la } \\
\text { movilidad social }\end{array}$ & $\begin{array}{c}\text { América } \\
\text { Latina }\end{array}$ \\
\hline Aldo Solari & $\begin{array}{l}\text { La universidad en transición en una sociedad } \\
\text { estancada: el caso del Uruguay }\end{array}$ & Uruguay \\
\hline Orlando Albornoz & Activismo político estudiantil en Venezuela & Venezuela \\
\hline Myron Glazer & $\begin{array}{l}\text { Las actitudes y actividades políticas de los } \\
\text { estudiantes de la Universidad de Chile }\end{array}$ & Chile \\
\hline $\begin{array}{l}\text { Gludio A. Dillon } \\
\text { Soares }\end{array}$ & $\begin{array}{l}\text { El mundo de la ideología; la función de las } \\
\text { ideas y la legitimidad de la política } \\
\text { estudiantil }\end{array}$ & Brasil \\
\hline Juan Osvaldo Inglese & $\begin{array}{l}\text { El poder socializador de las instituciones } \\
\text { educativas argentinas }\end{array}$ & Argentina \\
\hline Marialice Foracchi & Estudiante y política en el Brasil & Brasil \\
\hline
\end{tabular}

Solari, Aldo. Estudiantes y política en América Latina. Caracas: Monte Ávila Editores, 1967. 
Finalmente, en el contexto de las compilaciones sobre las luchas de movimientos estudiantiles, en el 2011, debido a la agitación de estas luchas durante estos años, se realizó otra colección de artículos relacionados con los movimientos estudiantiles. En esta ocasión, la obra fue auspiciada por un actor colectivo académico, el Observatorio Social en América Latina (OSAL), instancia que forma parte del Consejo Latinoamericano de Ciencias Sociales (CLACSO).

Cuadro 6. Compilación de artículos realizada por OSAL-CLACSO, 2011

\begin{tabular}{|l|l|c|}
\hline Autor / Autora & \multicolumn{1}{|c|}{ Artículo } & $\begin{array}{c}\text { País / } \\
\text { Región }\end{array}$ \\
\hline Hernán Ouviña & $\begin{array}{l}\text { Entrevista: Somos la generación que perdió el } \\
\text { miedo. Entrevista a Camila Vallejo Dowling }\end{array}$ & Chile \\
\hline Juan Urra Rossi & $\begin{array}{l}\text { La movilización estudiantil chilena en 2011: } \\
\text { una cronología }\end{array}$ & Chile \\
\hline $\begin{array}{l}\text { Carlos Durán } \\
\text { Migliardi }\end{array}$ & $\begin{array}{l}\text { El acontecimiento estudiantil y el viraje del } \\
\text { proceso sociopolítico chileno }\end{array}$ & Chile \\
\hline Daniel Núñez & $\begin{array}{l}\text { Proyecciones políticas del movimiento social } \\
\text { por la educación en Chile }\end{array}$ & Chile \\
\hline Mauricio Archila & $\begin{array}{l}\text { El movimiento estudiantil en Colombia, una } \\
\text { mirada histórica }\end{array}$ & Colombia \\
\hline $\begin{array}{l}\text { Pablo Bonavena y } \\
\text { Mariano Millán }\end{array}$ & $\begin{array}{l}\text { El movimiento estudiantil en la actualidad } \\
\text { argentina: una aproximación sociohistórica }\end{array}$ & Argentina \\
\hline Ricardo Vega Ruiz & $\begin{array}{l}\text { La defensa de la Universidad Autónoma de la } \\
\text { Ciudad de México frente a la contrarreforma } \\
\text { neoliberal }\end{array}$ & México \\
\hline Mina Navarro & La hora americana & Argentina \\
\hline
\end{tabular}

Gentili, Pablo y Emir Sader (compiladores). OSAL, Observatorio social de América Latina (Año XIII no. 31 mayo 2012). Buenos Aires: CLACSO, 2012. 